\title{
Magnetic Fluid Hyperthermia as Treatment Option for Pancreatic Cancer Cells and Pancreatic Cancer Organoids
}

\author{
Julian Palzer (i) ${ }^{1,2}$ \\ Benedikt Mues ${ }^{2}$ \\ Richard Goerg $\mathbb{D}^{1,2}$ \\ Merel Aberle $\mathbb{D}^{3}$ \\ Sander S Rensen ${ }^{3}$ \\ Steven WM Olde Damink (ID) \\ Rianne DW Vaes ${ }^{3}$ \\ Thorsten Cramer ${ }^{1,3}$ \\ Thomas Schmitz-Rode (D) $^{2}$ \\ Ulf P Neumann ${ }^{1,3}$ \\ loana Slabu ${ }^{2}$ \\ Anjali A Roeth (iD) ${ }^{1,3}$ \\ 'Department of General, Visceral and \\ Transplant Surgery, RWTH Aachen \\ University Hospital, Aachen, Germany; \\ ${ }^{2}$ Institute of Applied Medical Engineering, \\ Helmholtz Institute Aachen, RWTH \\ Aachen University Hospital, Aachen, \\ Germany; ${ }^{3}$ Department of Surgery, \\ NUTRIM School of Nutrition and \\ Translational Research in Metabolism, \\ Maastricht University, Maastricht, the \\ Netherlands
}

Introduction: Pancreatic ductal adenocarcinoma (PDAC) is a cancer with a meager prognosis due to its chemotherapy resistance. A new treatment method may be magnetic fluid hyperthermia (MFH). Magnetoliposomes (ML), consisting of superparamagnetic iron oxide nanoparticles (SPION) stabilized with a phospholipid-bilayer, are exposed to an alternating magnetic field (AMF) to generate heat. To optimize this therapy, we investigated the effects of MFH on human PDAC cell lines and 3D organoid cultures.

Material and Methods: ML cytotoxicity was tested on Mia PaCa- 2 and PANC- 1 cells and on PDAC 3D organoid cultures, generated from resected tissue of patients. The MFH was achieved by AMF application with an amplitude of $40-47 \mathrm{kA} / \mathrm{m}$ and a frequency of $270 \mathrm{kHz}$. The MFH effect on the cell viability of the cell lines and the organoid cultures was investigated at two different time points. Clonogenic assays evaluated the impairment of colony formation. Altering ML set-ups addressed differences arising from intra- vs extracellular ML locations.

Results: Mia PaCa-2 and PANC-1 cells showed no cytotoxic effects at ML concentrations up to $300 \mu \mathrm{g}(\mathrm{Fe}) / \mathrm{mL}$ and $225 \mu \mathrm{g}(\mathrm{Fe}) / \mathrm{mL}$, respectively. ML at a concentration of $225 \mu \mathrm{g}(\mathrm{Fe}) / \mathrm{mL}$ were also non-toxic for PDAC organoid cultures. MFH treatment using exclusively extracellular ML presented the highest impact on cell viability. Clonogenic assays demonstrated remarkable impairment as long-term outcome in MFH-treated PDAC cell lines. Additionally, we successfully treated PDAC organoids with extracellular ML-derived MFH, resulting in notably reduced cell viabilities $2 \mathrm{~h}$ and $24 \mathrm{~h}$ post treatment. Still, PDAC organoids seem to partly recover from $\mathrm{MFH}$ after $24 \mathrm{~h}$ as opposed to conventional 2D-cultures.

Conclusion: Treatment with MFH strongly diminished pancreatic cancer cell viability in vitro, making it a promising treatment strategy. As organoids resemble the more advanced in vivo conditions better than conventional 2D cell lines, our organoid model holds great potential for further investigations.

Keywords: magnetic nanoparticles, SPION, pancreatic cancer, PDAC, organoids, magnetic fluid hyperthermia

\section{Introduction}

Pancreatic ductal adenocarcinoma (PDAC) is one of the most lethal cancer entities worldwide amounting to a total of 432.000 death counts annually ${ }^{1}$ and, therefore, accounting for the seventh leading cause of cancer deaths. In western countries, such as the USA or Germany, PDAC ranks even higher. It takes place four in terms of cancer-related death causes. ${ }^{2}$

With an overall relative 5-year survival of merely $4-8 \%$ on an average and a mortality rate of dramatic $98 \%$, PDAC stands for a particularly meager
Correspondence: Anjali A Roeth

Email aroeth@ukaachen.de 
prognosis. ${ }^{2-4}$ This circumstance may primarily be attributed to a late diagnosis as well as an extreme resistance to radio- and chemotherapy found in this type of cancer. ${ }^{5,6}$ Due to the synergistic effect of increasing incidence in combination with a stagnation in therapy success, PDAC is expected to become the second leading cancer-related death cause by the year $2030 .^{7}$ Over the past few years, the urge to find new treatment methods against tumor cells has given rise to some alternative therapy strategies. Among them, thermal ablation strategies, such as magnetic fluid hyperthermia (MFH), gained much attention. ${ }^{8-12} \mathrm{MFH}$ is a thermal treatment method using the combination of a high-frequency $(\sim 100-500 \mathrm{kHz})$ alternating magnetic field (AMF) and magnetic nanoparticles (MNP) ${ }^{13,14}$ to generate heat through Brownian motion and Néel relaxation. Therefore, it is causing potent cellular damage to their immediate environment. ${ }^{15-18}$ Amidst the nanoparticles applied in MFH, especially magnetoliposomes (ML) present extraordinary characteristics in terms of biocompatibility as well as heating potential. ${ }^{12,19}$ They consist of superparamagnetic iron oxide nanoparticles (SPION) coated with a phospholipid bilayer. This coating layer not only serves the purpose of enhancing their biocompatibility but also provides an opportunity to augment these particles with additional theranostic substances ${ }^{20}$ or exclusively therapeutic substances such as chemotherapeutics like gemcitabine, which has been shown to be eminently augmented in efficiency by intracellular delivery. ${ }^{21}$ In experimental settings, this beneficial synergistic effect has shown a particularly promising perspective in pancreatic cancer therapy regarding precise tumor targeting of chemotherapeutic agents in terms of augmented accumulation of the tumor site ${ }^{9}$ and, thereby, inevitably reducing chemotherapeutic dosage by increasing treatment efficiency. ${ }^{22}$ Extensive research on the applicability of MFH treatment on various cancer types led to the attribution of MFH with promising properties in terms of efficiency and applicability. ${ }^{24-27}$ As such, MFH has already been used to treat glioblastoma in Phase II studies as well as in prostate or breast cancer. ${ }^{28-32}$

In most cases, the magnetic nanoparticles (MNP) are injected directly into the tumor to achieve high local concentrations of MNP of up to $80 \mathrm{mg}$ iron $(\mathrm{Fe}) / \mathrm{mL}$ tumor. ${ }^{32}$ This holds the risk of tumor spreading and of formation of metastases due to the puncture of the tumor. A different method is the injection of NP into a peripheral vein which are then targeted at the tumor site by magnetic field trapping. By this method, concentrations of $150-400 \mu \mathrm{g}(\mathrm{Fe}) / \mathrm{g}$ tumor can be achieved. ${ }^{31,33}$ We have recently shown in a biophysical model of the tumor and its surroundings that targeting the MNP at the tumor site is also possible by endoscopically placing the magnetic field trap to reach tumors inside the body. ${ }^{34}$ Building on this concept, we designed our experimental set-up of applying ML. We distinguished between two different clinical settings: one, where the AMF is applied directly after accumulation of the ML at the tumor site and one, where there is some time for incubation of the ML in the cells. ${ }^{35}$

One of the latest advances in the field of MFH treatment of pancreatic cancer cell is a study demonstrating a high efficiency of MFH treatment on cell line-derived three-dimensional hetero-type pancreatic cancer tumors, so-called spheroids. ${ }^{36}$ Although these spheroids are more advanced than conventional 2D cell cultures, they are still derived from immortalized conventional cell lines.

A more advanced three-dimensional in vitro model are organoids made from resected tumor tissue of patients. They are capable of mirroring the specific characteristics of their native tumor entity, therefore, resembling the primary tumor as a "mini-organ". Such organoids possess the ability to represent the variety of cell types constituting the original tumor as well as enabling the complex cellular cross-talk occurring in the native tumor environment. ${ }^{37}$ Based on this, and, due to the circumstance that organoids are highly stable in geno- as well as phenotype, ${ }^{38}$ organoids derived from specific tissues appear to maintain their distinct response pattern to external influences such as therapeutic substances or treatments like chemotherapeutics. ${ }^{39}$ Therefore, organoids have been exploited for testing of therapy sensitivity ${ }^{37,39,40}$ and personalized treatment approaches. ${ }^{41}$ The pancreatic tumor organoid model used in this study was developed in $2015^{42}$ and MFH treatment of PDAC organoids was employed to address the feasibility of MFH treatment of 3D PDAC structures with respect to future clinical implementation.

In case of PDAC, presently, the only curative treatment approach is the resection. Unfortunately, only $20 \%$ of the tumors are resectable at the time of diagnosis, often due to locally advanced tumors, which infiltrate the superior mesenteric artery. ${ }^{5}$ In the present study, we aim at a neoadjuvant setting to downsize the tumor and to achieve secondary resectability by use of MFH focused around the superior mesenteric artery. For this, the magnetic field trap for targeting of the MNP will be placed at the posterior wall of the stomach as the pancreas is located 
directly behind. We have shown by clonogenic assays that the human PDAC cell line Mia Paca-2 can successfully be treated with MFH. This effect is dependent on the duration of treatment and the bulk temperature. Best results could be found at temperatures higher than $41.5{ }^{\circ} \mathrm{C}$ and a treatment duration of 90 minutes. ${ }^{12,23,43}$

To optimize this therapy further and to distinguish between short- and long-term effects, we assessed the effects of MFH on different pancreatic cancer cells in vitro. We used different conventional 2D PDAC cell lines to investigate the effect's dependency on different cell lines. In addition, we treated 3D organoids as a more complex in vitro model for the first time with $\mathrm{MFH}$, thereby resembling the actual in vivo setting more precisely.

\section{Materials and Methods Cell Culture}

The human pancreatic cancer cell lines $\mathrm{Mia} \mathrm{PaCa}-2$ and PANC-1 were obtained from the German Collection of Microorganisms and Cell Cultures. Cell lines were routinely tested for mycoplasma contamination. Both cell lines were cultivated using high-glucose Dulbecco's Modified Eagle Medium (DMEM) containing 10\% fetal calf serum (FCS) and $1 \%$ Penicillin $(10000 \mathrm{U} / \mathrm{mL})$ and $1 \%$ Streptomycin $(10000 \mathrm{U} / \mathrm{mL})$. Cells were incubated in cell flasks at $37^{\circ} \mathrm{C}$ and $5 \% \mathrm{CO}_{2}$ and passaged every 3 to 4 days.

\section{PDAC Organoid Culture}

PDAC organoid cultures were generated from resected tissue according to the protocol of Boj et al. ${ }^{42}$ After ethical approval by the local ethics committee (Medical ethics review committee of the Academic Hospital Maastricht and Maastricht University, METC-AzM 13-04-107) and prior to tissue use, informed consent of the patients was obtained. All experiments were conducted in accordance with the Declaration of Helsinki. To generate organoid cultures from resected PDAC tissue, single cells were isolated from the resected specimen by digestion using collagenase type II. Isolated pancreatic cancer cells were then resuspended in ice-cold 'Geltrex ${ }^{\mathrm{TM}}$ LDEV-Free Reduced Growth Factor Basement Membrane Matrix' (Thermo Fisher Scientific, Waltham, WA, USA) transferred to a 24-well plate and supplied with Advanced DMEM/F-12-based Wnt3a-depleted organoid growth medium containing growth factors essential for organoid formation as described previously. ${ }^{44}$ These single cells formed organoids whilst incubating at $37{ }^{\circ} \mathrm{C}$ and $5 \%$ $\mathrm{CO}_{2}$ within 1 or 2 weeks. Organoids were passaged every 3-8 days with typical split ratios of $1: 2$ or $1: 4$. Passaging of the organoids was conducted as described previously. $^{44}$

\section{Magnetoliposomes and in vitro Magnetic Fluid Hyperthermia (MFH) Treatment}

Magnetic fluid hyperthermia (MFH) was achieved by the combination of magnetoliposomes (ML) containing superparamagnetic iron oxide nanoparticles (SPION) with a high-frequency alternating magnetic field (AMF) of $270 \mathrm{kHz}$ and varying amplitudes ranging from $40 \mathrm{kA} / \mathrm{m}$ to $47 \mathrm{kA} / \mathrm{m}$. ML were created from SPION by adding a surrounding phospholipid bilayer as previously reported by Hodenius et al. ${ }^{45}$ Evaluation of core size distribution was performed by transmission electron microscopy (TEM) using a Zeiss LEO 906 microscope (Carl Zeiss $\mathrm{GmbH}$, Oberkochen, Germany) at a magnification of 100000x. The hydrodynamic diameter distribution was evaluated by dynamic light scattering (DLS) using Zetasizer Nano S (Malvern Instruments Ltd., Worcestershire, United Kingdom) at a wavelength of $\lambda=$ $633 \mathrm{~nm}$ (detection angle of 173 ) (Supplementary Figures $\underline{\mathrm{S} 1}$ and $\underline{\mathrm{S} 2}$ ). Magnetization properties of the ML were investigated using a superconducting quantum interference device (SQUID) magnetometer MPMS 5S (LOT Quantum Design, San Diego, USA) (Supplementary Figure S3). Additionally, MFH measurements were performed using a custom build hyperthermia setup (Trumpf Hüttinger $\mathrm{GmbH}+\mathrm{Co}$. KG, Freiburg, Germany) by applying an AMF for a duration of 30 minutes starting at temperature $\mathrm{T}_{0}=37{ }^{\circ} \mathrm{C}$. (Supplementary Figure S4). The AMF was generated in a copper coil with internally water-cooled windings using an AC-resonant oscillator of a custombuilt hyperthermia setup (Trumpf Hüttinger, Freiburg, Germany). During MFH treatment, the temperature was continuously measured at the bottom of the hyperthermia vial, where the cells adhered, using a fiberoptic thermometer (Luxtron 812 from LumaSense Technologies; Santa Clara, CA, USA).

\section{Cell Viability Analysis Using the ATP-Based CellTiter Glo 2D/3D Cell Viability Assay}

After MFH treatment, the effects on the cell viability were determined using the ATP-based CellTiter Glo 2D/3D Cell 
Viability Assay (Promega Corporation, Madison, WI, USA) according to the protocol provided by the manufacturer. Eventually, luminescence was measured by a Synergy HT Microplate Reader from BioTek Instruments Inc. (BioTek Instruments Inc., Winooski, VT, USA). Cell samples analyzed at 0 hours post treatment were handled as described above immediately after MFH application. For cell samples analyzed at 24 hours post treatment, the supernatant containing the ML was replaced by fresh DMEM media immediately after the treatment, followed by a 24 -hour incubation period at $37{ }^{\circ} \mathrm{C}$ and $5 \%$ $\mathrm{CO}_{2}$.

\section{Quantification of Cell Reproducibility Using Clonogenic Assays}

Clonogenic Assays were performed according to the protocol of Franken et al. ${ }^{46}$ For this, cells were seeded at 400 cells per well in triplicates into a 6-well plate (Greiner Bio-One; Frickenhausen, Germany) in DMEM containing 10\% FCS and 1\% Penicillin (10000 U/mL)/Streptomycin (10000 U/mL) upon MFH treatment. The assay was stopped after $8-10$ days using $1 \mathrm{~mL}$ of a (1:10) methanol (70\%)/Crystal Violet mix per well. After incubating for 30 minutes, the crystal violet solution was removed and the wells were washed twice with $3 \mathrm{~mL}$ of water. After overnight drying, colonies were counted by two independent investigators and plating efficiency and survival fraction were determined. ${ }^{46}$

\section{Cytotoxicity Testing of ML}

ML were tested for cytotoxicity on human pancreatic cancer cell lines Mia PaCa-2 and PANC-1 at concentrations of $(0,150,225,300$ and 450$) \mu \mathrm{g}(\mathrm{Fe}) / \mathrm{mL}$ after 24 hours of incubation at $37{ }^{\circ} \mathrm{C}$ and $5 \% \mathrm{CO}_{2}$. For each concentration, a triplet of samples was prepared. Thirty minutes prior to cell viability analysis, a DMEM/DMSO solution containing 38\% DMSO was added to the wells of the negative control to induce cell death. Eventually, the supernatant was replaced by $100 \mu \mathrm{L}$ of DMEM immediately before cell viability was analyzed using the CellTiter Glo Assay as described above. The replacement was done as pre-experiments had shown that the ML would otherwise interfere with the luminescent signal (data not shown).

Cytotoxic effects on patient-derived PDAC organoids were examined at a concentration of $225 \mu \mathrm{g}(\mathrm{Fe}) / \mathrm{mL}$. Here, the organoids were seeded in Geltrex ${ }^{\mathrm{TM}}$ droplets in a 48- wells plate. The following day, the supernatant was replaced either by organoid growth medium, organoid growth medium/DMSO solution containing 38\% DMSO, or organoid growth medium containing $\mathrm{ML}$ at a concentration of $225 \mu \mathrm{g}(\mathrm{Fe}) / \mathrm{mL}$. After 24-hours incubation, cell viability was quantified using the CellTiter Glo Assay as described above.

\section{Effects of MFH on Mia PaCa-2 and PANC-I}

To investigate the effects of $\mathrm{MFH}$ regarding the location of the ML with respect to the cells, four different approaches were applied:

- No ML, ie, just the AMF

- Intracellular ML (incubation with an ML solution of $225 \mu \mathrm{g}(\mathrm{Fe}) / \mathrm{mL}$ for $24 \mathrm{~h}$ followed by washing with DPBS prior to transferring into hyperthermia vials in DMEM)

- Intra- and extracellular ML (incubation with an ML solution of $225 \mu \mathrm{g}(\mathrm{Fe}) / \mathrm{mL}$ for $24 \mathrm{~h}$, washing with DPBS, resuspending in the same solution used for incubation and bringing them into the hyperthermia vials)

- Extracellular ML (no pre-incubation with ML but resuspension in an ML solution of $225 \mu \mathrm{g}(\mathrm{Fe}) / \mathrm{mL}$ immediately before transferring them into the hyperthermia vials)

Figure 1 depicts the experimental set-up of the approaches containing ML. Each approach consisted of a sample treated with AMF as well as a control sample. The control sample was placed on a hotplate set to $37{ }^{\circ} \mathrm{C}$ for 90 minutes, while the MFH-treated sample was exposed to 90 minutes of AMF.

After the treatment, the effects of MFH on cell viability were analyzed at 0 and 24 hours using the CellTiter Glo Assay. Cell reproducibility was evaluated via Clonogenic Assay.

\section{Geltrex ${ }^{T M}$ Set-Up for Organoids Experiments}

Two set-ups were tested: one sample comprising a Geltrex ${ }^{\mathrm{TM}}$ droplet of one-tenth of the overall sample volume, and another sample containing the same amount of Geltrex ${ }^{\mathrm{TM}}$ but homogenously suspended in the sample solution. Prior to 30-minutes AMF treatment, both 


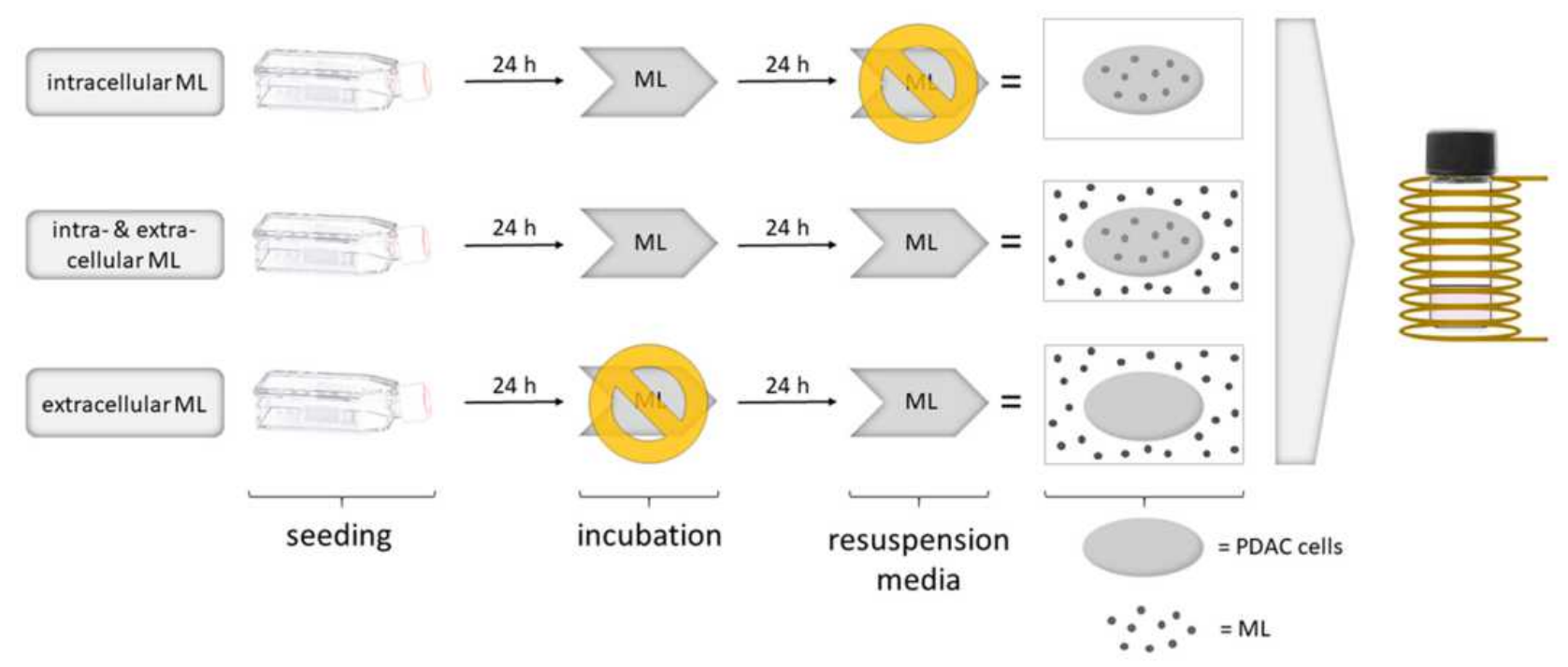

Figure I Experimental set-up of 2D cell culture MFH trials.

samples received an equal volume of medium containing ML $(225 \mu \mathrm{g}(\mathrm{Fe}) / \mathrm{mL})$. The temperature at the bottom of the vial was recorded using a fiberoptic thermometer.

\section{Interaction with Organoids}

To gain information on the interaction of ML with organoids, we investigated three different approaches:

(i) One approach carrying no ML at all, therefore serving as a 'negative control'

(ii) One approach incubated with ML for 2 hours representing the actual MFH 'experimental conditions'

(iii) One approach where ML were applied after the washing steps of the embedding protocol and immediately before fixation of the organoids, to mimic an approach without an incubation time. As the ML were not washed away with this approach, visible ML were ensured, thereby serving as a 'positive control'

\section{Organoid Embedding and (Immunohistochemistry) Staining}

After individual treatment as described above, fixation of the organoids were employed by administration of the zinc formalin fixative Unifix (Klinipath, Duiven, The Netherlands) for 30 minutes. Next, Unifix was washed off and replaced with $70 \%$ ethanol before resuspension in heated liquid Histogel ${ }^{\mathrm{TM}}$ (Thermo Fisher Scientific,
Waltham, WA, USA). After storage at $4^{\circ} \mathrm{C}$ for 1 hour, the Histogel ${ }^{\mathrm{TM}}$ was placed in $70 \%$ ethanol. Further FFPE (formalin-fixated paraffine-embedded) treatment was performed by the pathology department of UMC+ by dehydration of the organoids with subsequent paraffine embedding. After cutting, slides were obtained for further staining.

Haematoxylin and eosin (HE) staining was performed by staining with hemalaun followed by counterstaining with eosin. As ML contain iron oxides, Prussian blue staining was used for visualization of the ML. Prussian blue staining was conducted by the pathology department of RWTH Aachen University Hospital by staining with Berliner Blau (Merck KGaA, Darmstadt, Germany), counterstaining with Kernechtrot (Merck KGaA, Darmstadt, Germany; Waldeck GmbH \& Co. KG, Muenster, Germany) and then dehydration in an ascending alcohol series.

For immunohistological analysis, we used the ZytoChem-Plus AP Polymer-Kit (Zytomed Systems $\mathrm{GmbH}$, Bargteheide, Germany) according to the manufacturer's directions. Sample slides were treated with the primary antibodies and then counterstained with hemalaun. Antibodies used for immunohistochemistry (IHC) staining were anti-CK (Cytokeratin) antibodies (Dako Denmark A/S, Glostrup, Denmark) for verification of cell differentiation, anti-Ki67 antibodies (Dako Denmark A/S, Glostrup, Denmark) for cell proliferation rate evaluation and anti-CC3 (Cleaved Caspase-3) antibodies (abcam, Cambridge, United Kingdom) for apoptosis 
detection. The TissueFAXS PLUS system (TissueGnostics, Vienna, Austria) was used for imaging and qualitative evaluation. Quantitative analysis of Ki67-expression and CC3-expression was performed with StrataQuest Analysis Software (TissueGnostics, Vienna, Austria).

\section{Cell Viability Testing of MFH-Treated Patient-Derived PDAC Organoids}

Similar to the cell lines, each approach consisted of a sample treated with AMF as well as a control sample which remained on a hotplate at $37^{\circ} \mathrm{C}$. Organoids derived from the organoid forming line PANCO- $9 \mathrm{a}^{44}$ were treated either with an AMF in the absence of any ML ('no ML + $\mathrm{AMF}^{\prime}$ ) or, as a second approach, comprised of 'extracellular $\mathrm{ML}^{\prime}$ which were added in a concentration of 225 $\mu \mathrm{g}(\mathrm{Fe}) / \mathrm{mL}$ before $\mathrm{MFH}$ treatment.

Seeding of the organoids into hyperthermia vials was performed by suspending them in ice-cold Advanced DMEM/F-12 medium and centrifuging at $4{ }^{\circ} \mathrm{C}$ and 145 rcf for 5 minutes. After centrifugation, organoids were resuspended in Geltrex ${ }^{\mathrm{TM}}$. Seeding of the organoids was done by placing a droplet of $50 \mu \mathrm{L}$ on the bottom of four pre-heated hyperthermia vials each. After each droplet, a 'control droplet' of $15 \mu \mathrm{L}$ was placed into wells of a 48well plate, to evaluate and ensure equal distribution of the organoids in the hyperthermia vials. After adding the Advanced DMEM/F-12-based Wnt3a-depleted organoid growth medium and overnight incubation at $37{ }^{\circ} \mathrm{C}$ and $5 \%$ $\mathrm{CO}_{2}$, the supernatant of the 'AMF samples' was replaced by DMEM while 'extracellular ML' samples received a DMEM/ML solution containing $\mathrm{ML}$ at a concentration of $225 \mu \mathrm{g}(\mathrm{Fe}) / \mathrm{mL}$. At the end of the treatment, all organoid cultures were washed with DBPS. Organoids undergoing immediate ( $2 \mathrm{~h}$ after MFH treatment) cell viability analysis were supplied with fresh organoid passaging medium, whereas samples evaluated at 24 hours after $\mathrm{MFH}$ treatment were supplied with organoid passaging medium containing human organoid growth medium. The latter were then incubated for 24 hours at $37{ }^{\circ} \mathrm{C}$ and $5 \% \mathrm{CO}_{2}$ before cell survival analysis. Cell survival was quantified using the CellTiter Glo Assay (Promega Corporation, Madison, WI, USA). The supernatant was replaced with fresh DMEM medium and the CellTiter Glo Assay essence was added at equal amount. Once the luminescence signal had stabilized, luminescence was measured using a Synergy HT Microplate Reader from BioTek
Instruments Inc. (BioTek Instruments Inc., Winooski, VT, USA).

\section{Statistical Analysis}

Statistical analysis was performed using Graphpad Prism 5 (GraphPad Software Inc., San Diego, CA, United States) and Microsoft Excel 2019 (Microsoft Corporation, Redmond, WA, USA). Statistical significance was evaluated by Student two-tailed $t$-test; significance levels of $\mathrm{p}<$ $0.05(*), \mathrm{p}<0.01(* *)$ and $\mathrm{p}<0.001(* * *)$ were assumed. Unless otherwise stated, all data in this report represent the mean value as well as the corresponding standard deviation from at least triplicate measurements. In cytotoxicity testing of ML, all samples were normalized to the control: $0 \mu \mathrm{g}(\mathrm{Fe}) / \mathrm{mL}$. Based on the non-toxicity of ML at 225 $\mu \mathrm{g}(\mathrm{Fe}) / \mathrm{mL}$ and intending to exclusively evaluate the effect of AMF application on each ML setting, 2D cell culture samples undergoing viability analysis were normalized to their method-specific control. For all other experiments, samples were normalized to the control ('no $\mathrm{ML}^{\text {' and }}$ no $\mathrm{AMF}$ ).

\section{Results \\ ML Characterization}

Table 1 summarizes the ML properties. The corresponding detailed data analysis is available in the Supplementary

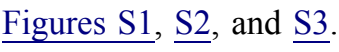

\section{Cytotoxicity Testing of ML}

Cytotoxicity testing of ML revealed different effects of ML on Mia PaCa-2 and PANC-1 cells. In fact, ML did not show any significant influence on Mia $\mathrm{PaCa}-2$ cells at

Table I Physico-Chemical Properties of ML Dispersed in TES Buffer: Hydrodynamic Diameter, Core Diameter, Saturation Magnetization, Magnetic Diameter, Peak Temperature in the ZFC Curve and Specific Absorption Rate

\begin{tabular}{|l|l|l|}
\hline Method & Property & Value \\
\hline DLS & Hydrodynamic diameter/nm & $100 \pm 49$ \\
\hline TEM & Core diameter $/ \mathrm{nm}$ & $11.1 \pm 2.5$ \\
\hline \multirow{2}{*}{ SQUID } & Saturation magnetization $/\left(\mathrm{Am}^{2} / \mathrm{kg}(\mathrm{Fe})\right)$ & $104 \pm \mathrm{I}$ \\
& Magnetic diameter $/ \mathrm{nm}$ & $10.3 \pm 2.9$ \\
& Peak temperature of $\mathrm{ZFC}$ curve $/ \mathrm{K}$ & $266 \pm 1$ \\
\hline \multirow{2}{*}{ MFH } & Specific absorption rate at $225 \mu \mathrm{gg}(\mathrm{Fe}) / \mathrm{mL}$, & $406 \pm 23$ \\
& $40 \mathrm{kA} / \mathrm{m}, 270 \mathrm{kHz} / \mathrm{W} / \mathrm{g}(\mathrm{Fe}))$ & \\
\hline
\end{tabular}

Note: Values are displayed with their standard deviation. 

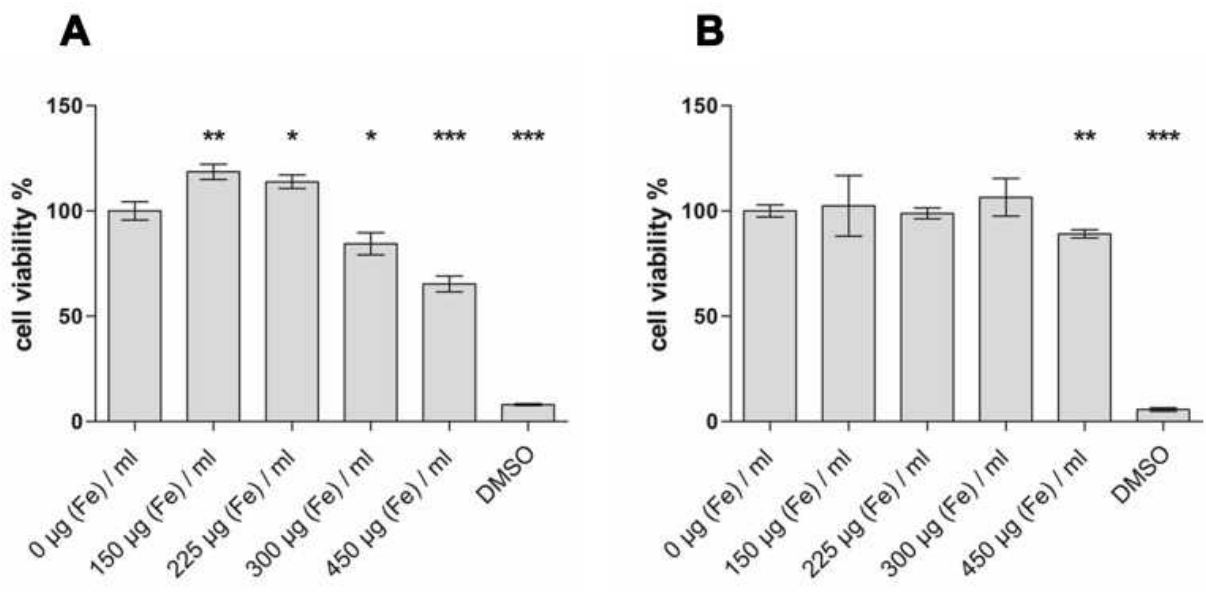

Figure 2 Cytotoxicity testing of increasing ML concentrations ranging from $0 \mu g(\mathrm{Fe}) / \mathrm{mL}$ to $450 \mu \mathrm{g}(\mathrm{Fe}) / \mathrm{mL}$ on human pancreatic ductal cancer PANC-I (A) and Mia PaCa-2 (B) cells revealed no cytotoxic effect at concentrations of up to $300 \mu \mathrm{g}(\mathrm{Fe}) / \mathrm{mL}$ and $225 \mu \mathrm{g}(\mathrm{Fe}) / \mathrm{mL}$, respectively $\left({ }^{*} \mathrm{p}<0.05\right.$, $* * \mathrm{p}<0.0 \mathrm{I}$, ***p $\left.<0.00 \mathrm{I}\right)$. All samples were normalized to the control group of $0 \mu \mathrm{g}(\mathrm{Fe}) / \mathrm{mL}$. Cell viability of greater than $100 \%$ is due to the normalization with respect to the control group.

concentrations of up to $300 \mu \mathrm{g}(\mathrm{Fe}) / \mathrm{mL}$ (Figure 2B), whereas PANC-1 cells treated with ML at concentrations of $150 \mu \mathrm{g}(\mathrm{Fe}) / \mathrm{mL}$ and $225 \mu \mathrm{g}(\mathrm{Fe}) / \mathrm{mL}$ even showed an increase in cell viability of $19 \%$ and $14 \%$ (Figure 2A), respectively. PANC-1 cells further displayed a decrease in cell viability of $16 \%$ upon 24-hour exposure with ML at a concentration of $300 \mu \mathrm{g}(\mathrm{Fe}) / \mathrm{mL}$. ML at a high concentration of $450 \mu \mathrm{g}(\mathrm{Fe}) / \mathrm{mL}$ showed significant cytotoxic effects in both cell lines accounting for an $11 \%$ decrease in the cell viability of $\mathrm{Mia} \mathrm{PaCa}-2$ cells and for a $35 \%$ decrease in PANC-1 cell samples. Based on the nontoxicity of ML at $225 \mu \mathrm{g}(\mathrm{Fe}) / \mathrm{mL}$ observed for both cell lines, $225 \mu \mathrm{g}(\mathrm{Fe}) / \mathrm{mL}$ was determined to be the concentration for the following MFH experiments.

\section{Cell Survival of MFH-Treated Mia PaCa-2 and PANC-I Cells}

To allow for precise investigation of the effects resulting from different ML locations, a concept of four different settings: 'no $\mathrm{ML}^{2}$, 'intracellular $\mathrm{ML}^{\prime}$, 'intra- and extracellular ML ' and 'extracellular ML' was designed. Investigating the potential immediate effects of MFH, cell viability was analyzed directly after application of ML. Solely extracellular MFH showed notable cytotoxic effects in both cell lines, as the cell viability of PANC-1 cells as well as the cell viability of Mia PaCa-2 cells decreased by $(21 \pm 2) \%$ upon MFH treatment, respectively (Figure 3A and B). The other groups showed no significant change upon MFH treatment.

Subsequently, cell viability analysis at 24 hours after the MFH treatment was applied to identify any time-dependent alterations of the observed effects over the course of the first 24 hours after the treatment. Here, exclusive AMF treatment showed different effects on the cell lines: AMF-treated Mia PaCa- 2 cells depicted an increase in cell viability of $13 \%$ (Figure 3C) whereas identically treated PANC-1 cells showed no significant change (Figure 3D). Analysis of cell samples exposed to intracellular MFH revealed no significant decrease for PANC-1. Treatment of PANC-1 cells with intra- and extracellular MFH ('intra- and extracellular ML + AMF') resulted in a marked drop in cell viability of $15 \%$ (Figure 3D) while identically treated Mia PaCa-2 cells (Figure 3C), contrastingly, showed no significant change. Matching our findings compiled at 0 hours post treatment, cell samples treated with extracellular ML-derived MFH ('extracellular $\left.\mathrm{ML}+\mathrm{AMF}^{\prime}\right)$ presented the most prominent cell death in both cell lines amounting to $27 \%$ in PANC-1 cell samples (Figure 3D) and 12\% in Mia PaCa-2 cell samples (Figure 3C).

\section{Clonogenic Potential of MFH-Treated Mia PaCa-2 and PANC-I Cells}

Clonogenic Assays as a long-term outcome provided information on the effects of MFH on the clonogenic potential of Mia PaCa-2 and PANC-1 cells which plays a pivotal role in tumor progression. Again, four different ML settings: 'no ML + $\mathrm{AMF}^{\prime}$, 'intracellular ML + $\mathrm{AMF}^{\prime}$, 'intra-and extracellular ML $+\mathrm{AMF}^{\prime}$ and 'extracellular ML $+\mathrm{AMF}^{\prime}$ were tested. Untreated cells with no ML and no AMF served as a control. Exclusive AMF application in the absence of any ML ('no ML $\left.+\mathrm{AMF}^{\prime}\right)$ had no significant effects on the clonogenic 

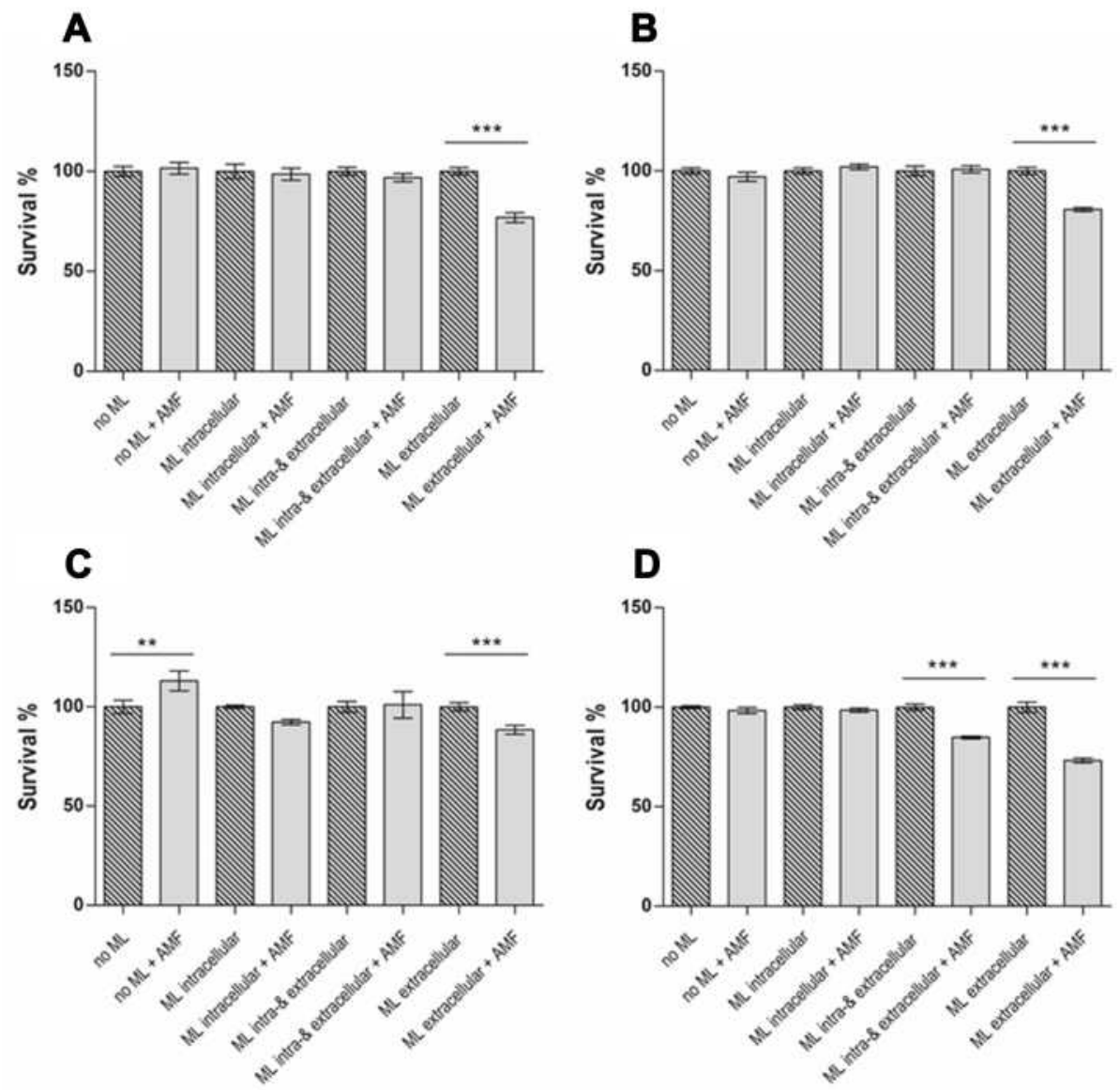

Figure 3 Cell viability of Mia PaCa-2 and PANC-I cells at 0 hours (A and $\mathbf{B}$ ) and 24 hours ( $\mathbf{C}$ and $\mathbf{D}$ ) after MFH treatment. Extracellular MFH ('extracellular ML + AMF') accounted for the most prominent decrease in cell viability at 0 hours $(\mathbf{A}$ and $\mathbf{B})$ as well as at 24 hours $(C$ and $D)$ after the treatment. This applied to both cell lines. $(* * \mathrm{p}<0.01, * * * \mathrm{p}<0.001)$.

potential of either Mia PaCa-2 or PANC-1 cells (Figure $4 \mathrm{~A}$ and $\mathrm{B})$.

Analysis of cell samples of either cell line treated with intracellular MFH demonstrated a decrease in clonogenic potential of $23 \%$ in both cell lines (Figure $4 \mathrm{~A}$ and B). Mia PaCa-2 cells exposed to intra- and extracellular MFH as well as extracellular MFH presented with a strong decrease in clonogenic potential each with nearly no residual clonogenic activity (Figure 4A). Identically treated PANC-1 cells also showed a strong, yet markedly less pronounced decrease in clonogenic potential than Mia $\mathrm{PaCa}-2$ cells of $33 \%$ and $52 \%$, respectively (Figure $4 \mathrm{~B}$ ).

\section{Heating Characteristics of Geltrex ${ }^{\mathrm{TM}}$}

Testing of the impacts of different Geltrex ${ }^{\mathrm{TM}}$ set-ups on the heating characteristics of MFH was employed to determine the most convenient set-up for the ensuing MFH experiments on human PDAC organoids. Comparison of a Geltrex ${ }^{\mathrm{TM}}$ droplet surrounded by a medium/ML solution (1:9) and Geltrex ${ }^{\mathrm{TM}}$ in a homogenous suspension with medium/ML solution (1:9) showed no significant difference regarding heat development as in both ways temperatures of $(43 \pm 1){ }^{\circ} \mathrm{C}$ were achieved (Figure 5).

\section{Organoid Microscopical Images}

Since 3D organoid cultures are considered a more relevant in vitro model of PDAC, we introduced, for the first time, ML to organoids. Figure 6A depicts patient-derived PDAC organoids under regular growth conditions. After $24 \mathrm{~h}$ of incubation with ML, the PDAC organoids did not show significant morphological alterations (Figure 6B).

\section{Cytotoxicity Testing of ML on Patient-Derived PDAC Organoids}

Prior to MFH treatment of PDAC organoids, verification of the non-toxicity of ML for human PDAC organoids was 

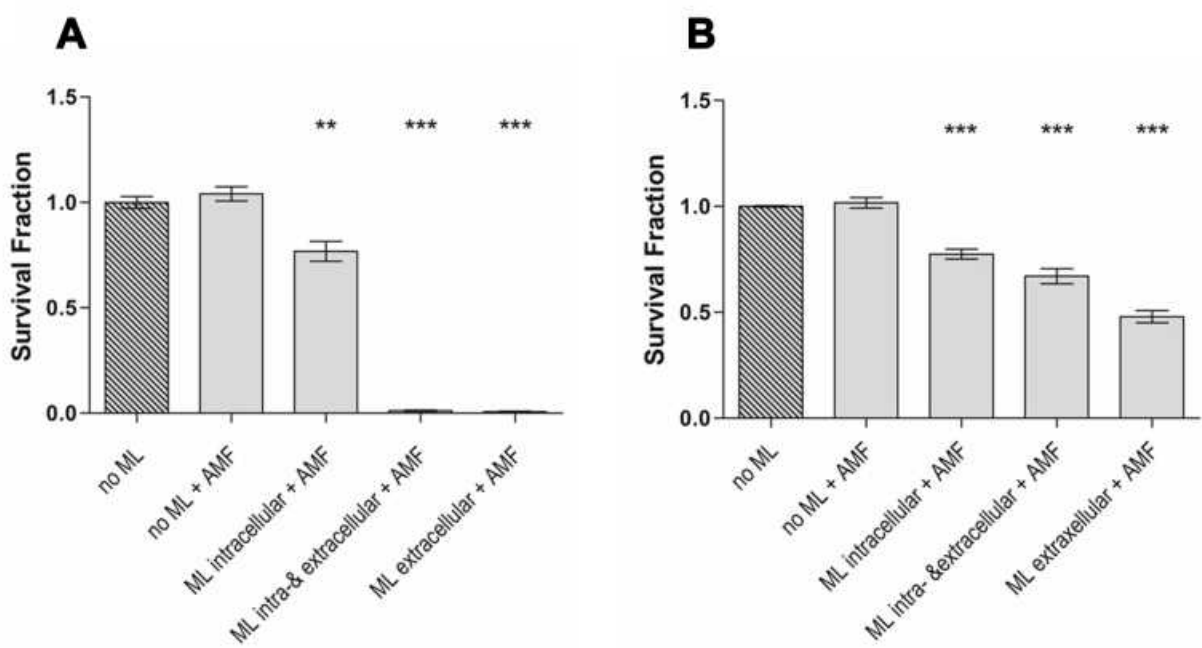

Figure 4 Survival fractions of MFH-treated Mia PaCa-2 (A) and PANC-I (B) as quantified by Clonogenic Assay after treatment. MFH treatment resulted in marked decrease in clonogenic potential of both cell lines for all set-ups with ML. Yet, this effect was most pronounced for samples treated with intra- and extracellular MFH as well as extracellular MFH. $\left(* * \mathrm{p}<0.01\right.$, $\left.{ }^{* * *} \mathrm{p}<0.001\right)$.
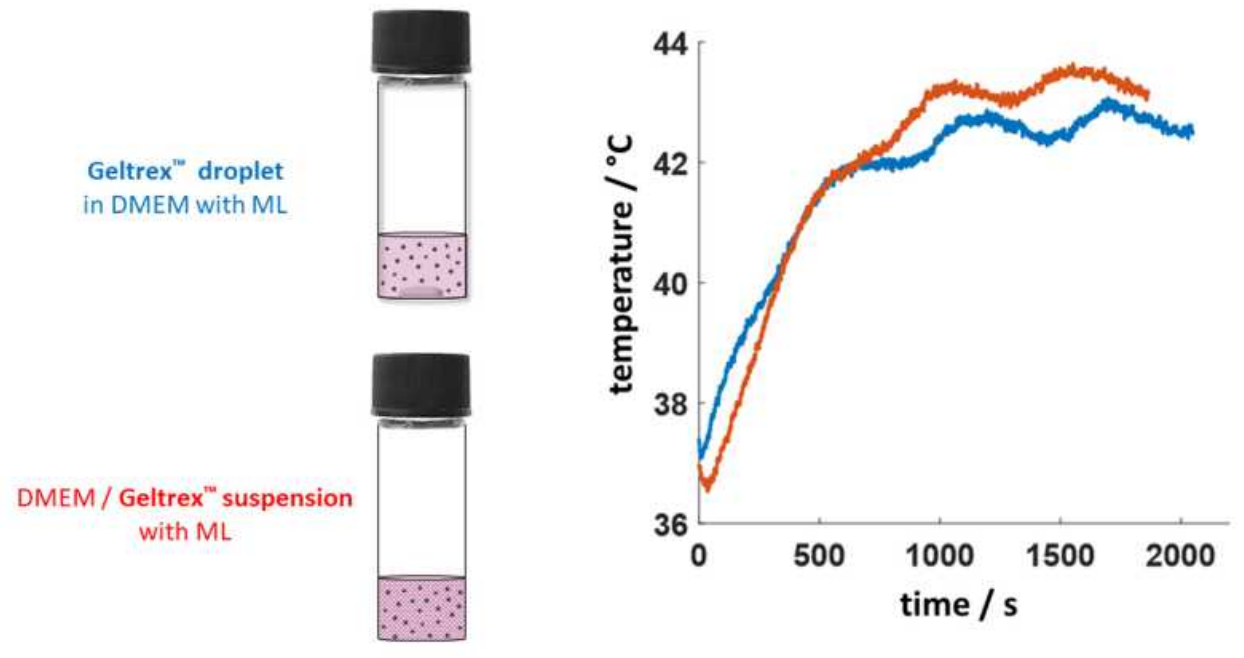

Figure 5 Heating characteristics of two different Geltrex ${ }^{\mathrm{TM}}$ set-ups.

imperative. Considering our results obtained in the 2D cell cultures, we chose a concentration of $225 \mu \mathrm{g}(\mathrm{Fe}) / \mathrm{mL}$ for MFH treatment of human PDAC organoids. Cell viability testing of human PDAC organoids treated with $\mathrm{ML}$ at 225 $\mu \mathrm{g}(\mathrm{Fe}) / \mathrm{mL}$ for 24 hours unveiled neglectable cytotoxic effects (Figure 7) with DMSO as positive control. Hence, hereafter, subsequent MFH treatment of human PDAC organoids was conducted using ML at a concentration of $225 \mu \mathrm{g}(\mathrm{Fe}) / \mathrm{mL}$.

\section{Interaction with Organoids}

Seeking information on the molecular interaction between ML and PDAC organoids, we assessed the morphological interaction of ML with PDAC organoids Prussian blue staining for iron. As visualized in Figure 8, ML appeared to only interact by adhesion to the cell surface of PDAC organoids without being internalized into the cells (Figure 8). Further, morphologic investigations using HE staining and IHC staining for CK (cell differentiation) revealed no difference between the three groups. To investigate molecular changes after incubation with $\mathrm{ML}$ as opposed to untreated ones further, we analyzed the Ki67 expression (proliferation) and the apoptosis-indicating CC3 expression. There were no significant alterations between the groups. Figure 8 demonstrates representative examples of the immunohistological findings. 


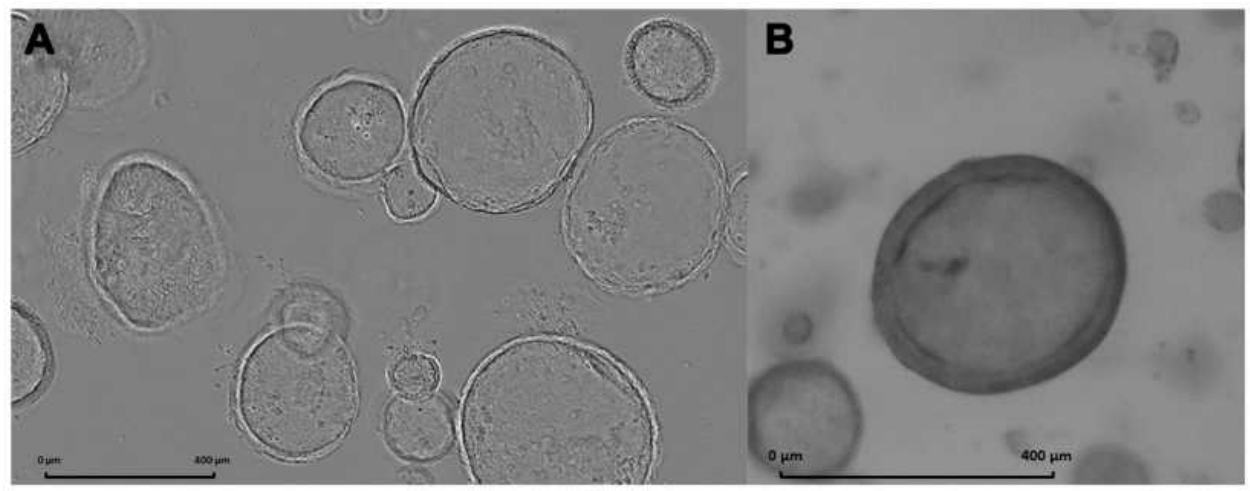

Figure 6 (A) Microscopical image of human patient-derived PDAC organoids portraying the characteristic 3D organoid structure. (B) Microscopical image of a human patient-derived PDAC organoid after 24 hours of incubation with nanoparticles.

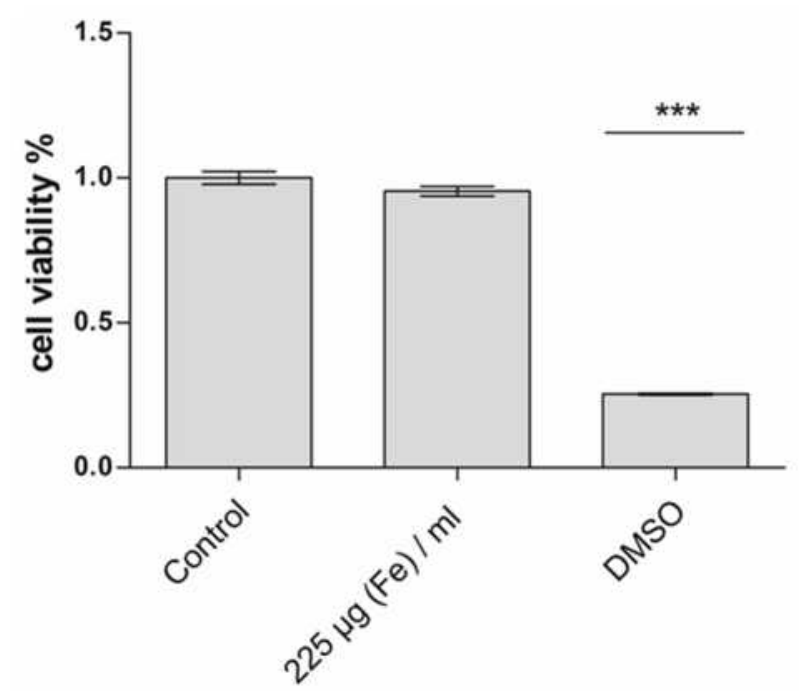

Figure 7 Cell viability testing of patient-derived PDAC organoids (PANCO-9a) after 24-hour incubation with $\mathrm{ML}$ at a concentration of $225 \mu \mathrm{g}(\mathrm{Fe}) / \mathrm{mL}$ showed neglectable cytotoxic effects. (***p $<0.00 \mathrm{I})$.

\section{Cell Survival of MFH-Treated PDAC Organoids}

Owing to the previously demonstrated impairment of cell survival by extracellularly located ML in terms of impairment of cell survival, MFH effects on patientderived PDAC organoids were assessed only by this approach. In addition, one sample underwent just AMF treatment without ML. Cell viability analysis at 2 hours post treatment demonstrated a severe decrease in cell viability of $48 \%$ (Figure 9A). At 24 hours after the treatment, the organoids treated with extracellular ML and AMF showed a 13\% decrease of cell viability compared to the control (Figure 9B). Treatment with an AMF alone revealed no significant change in cell viability at 2 hours post treatment and a slight increase at 24 hours post treatment.

\section{Discussion}

We assessed the short- as well as long-term cytotoxicity of magnetic fluid hyperthermia (MFH) in 2D cell cultures for two different cell lines, Mia PaCa-2 and PANC-1, as a proof of the concept and to further improve this therapy in detail. MFH was found to be a highly promising tool in PDAC therapy. A solely extracellular accumulation of ML seems to be sufficient, although an additional intracellular uptake plays an important role regarding the long-term cytotoxic effects of this therapy. Nonetheless, the efficiency of this therapy seems to be varying among genetically different PDAC subtypes. In addition, we showed, for the first time, that this therapy method is also suitable for more complex models such as human PDAC organoids, which resemble actual in vivo conditions such as histoarchitecture and microenvironment far more precisely than conventional cell lines. ${ }^{47}$ Given the novelty of MFH treatment of human PDAC organoids, we studied the interaction of the ML with PDAC organoids by HE staining, Prussian Blue staining and immunohistochemistry. With extracellularly placed ML, MFH significantly reduced the viability, thereby proving the applicability for future clinical implementation of MFH in patients.

\section{Applicability of MFH Treatment}

We demonstrated that ML showed no toxicity for concentrations of up to at least $225 \mu \mathrm{g}(\mathrm{Fe}) / \mathrm{mL}$ for both investigated cell lines (Figure 2). Interestingly, while Mia PaCa-2 cells did not show any significant alterations in cell viability after ML incubation at 150 and $225 \mu \mathrm{g}(\mathrm{Fe}) / \mathrm{mL}$ (Figure 2B), PANC-1 cells, however, reacted with a slight increase 


\section{Prussian Blue}

HE

CK

'negative

control' 'experiment conditions' 'positive

control'

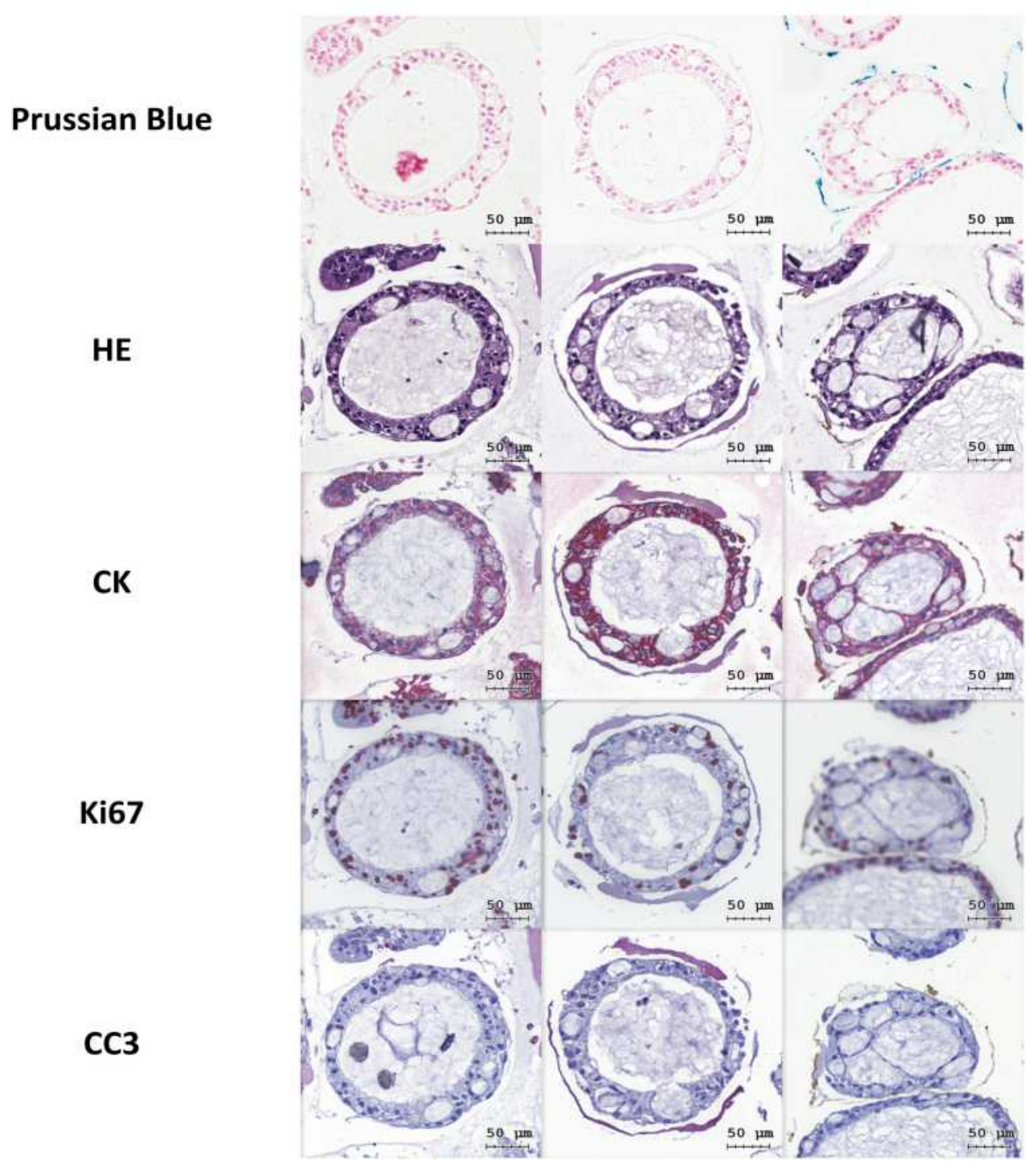

Figure 8 Exemplary histological images of ML interacting with PDAC organoids. Prussian blue staining highlights ML in blue in the 'positive control' sample. Immunohistochemistry staining for $\mathrm{Ki} 67$ and $\mathrm{CC} 3$ showed no significant alterations in cell proliferation rate and apoptosis rate in PDAC organoids upon ML treatment in comparison to native PDAC organoids. Exemplary organoids for each set-up are depicted.

in cell viability after $24 \mathrm{~h}$ (Figure 2A). As the viability test used is ATP-based, this might show increased ATP synthesis by the cells upon ML exposure. So far, increased cell division upon ML incubation but not increased cell viability has been reported prior to this observation in a model of C17.2 mouse stem cells. ${ }^{48}$ We propose that this increase in cell viability in this particular cell line may be hormesisrelated. Hormesis describes the beneficial adaptive response of cells exposed to a moderate dose of a potentially irritating agent. ${ }^{49}$ Further investigations regarding this aspect of PANC-1 are needed.
As the ML are envisaged to be administered intravenously before being accumulated at the tumor site by endoscopic magnetic trapping, ${ }^{34}$ only rather low concentrations of ML at the tumor site varying between 150 $\mu \mathrm{g}(\mathrm{Fe}) / \mathrm{g}$ tumor $^{31}$ and $400 \mu \mathrm{g}(\mathrm{Fe}) / \mathrm{g}$ tumor $^{33}$ will be achievable. Hence, the potentially toxic effect of higher concentrations of ML is not relevant as such high concentrations will most likely not be found for in vivo settings. As we have demonstrated before, ${ }^{12}$ ML already show potent heating characteristics at concentrations of $225 \mu \mathrm{g}$ (Fe)/mL. Therefore, we concluded ML at $225 \mu \mathrm{g}(\mathrm{Fe}) / \mathrm{mL}$ 

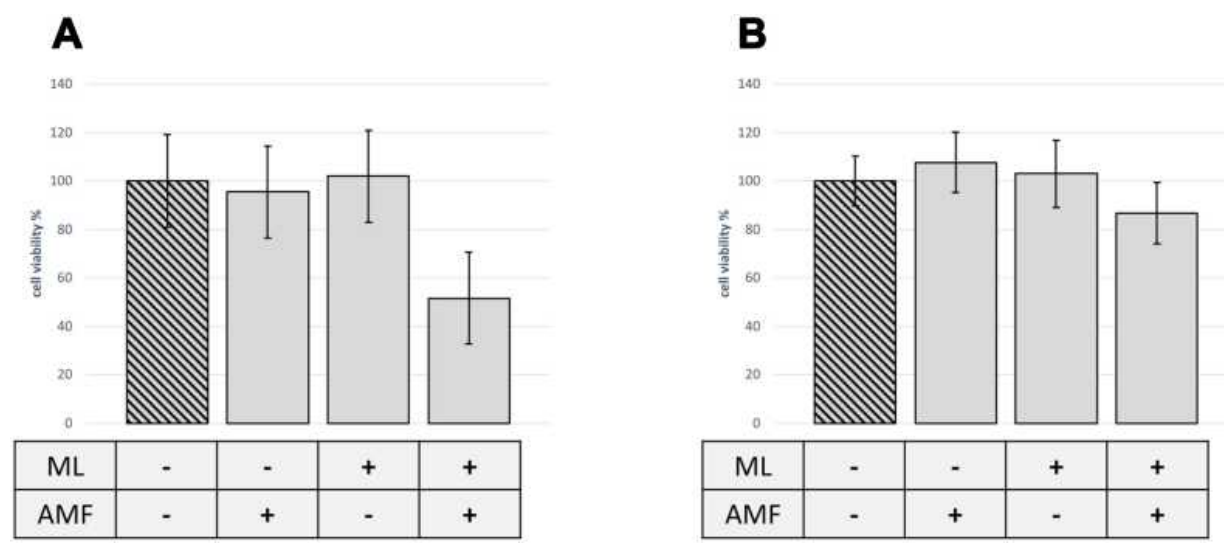

Figure 9 Cell survival of patient-derived PDAC organoids (PANCO-9a) upon MFH treatment. MFH-treated patient-derived PDAC organoids showed a decrease in cell viability of $48 \%$ at 2 hours post treatment (A) and of $13 \% 24$ hours post treatment (B), respectively. All samples were normed to the control: 'no ML'.

to be the concentration of choice for all our further MFH experiments.

\section{MFH Experimental Set-Up}

Although ML internalization starts within the first few minutes upon ML incubation, ${ }^{35}$ only a negligible amount is internalized when the ML are administered just before treatment. This relates to the clinical setting, where the AMF is applied shortly after the ML have been targeted in a sufficient amount by the magnetic field trap. ${ }^{31,34}$ In contrast, the ML in the 'intra-and extracellular' group were administered $24 \mathrm{~h}$ before treatment, allowing for saturation internalization of $\mathrm{ML}^{35,50}$ This, on the other hand, relates to the future clinical setting of waiting for a longer time after accumulation of the ML at the tumor site before AMF treatment with the advantage of possible intracellular delivery of chemotherapeutic agents. Finally, the path with only intracellular ML (after $24 \mathrm{~h}$ of incubation) served to investigate the effects of nanoheating without a corresponding clinical setting. Nanoheating describes a phenomenon occurring in intracellular hyperthermia, where solely the nanoparticles and their immediate nano-environment show a marked temperature increase with a plus of up to $30{ }^{\circ} \mathrm{C}$ above the temperatures detected on a macroscopic scale. ${ }^{51}$ Opposingly, bulk temperature dependent cytotoxicity describes cytotoxic effects causally related to macroscopically detectable temperature elevations. Commonly, bulk temperature dependent cytotoxicity is related to surpassing a defined temperature threshold. This threshold is thought to be above $43{ }^{\circ} \mathrm{C}$ in clinical settings. ${ }^{29,52}$ However, experimental data also state the sufficiency of even lower temperatures of above $41.5^{\circ} \mathrm{C} .{ }^{12,43}$ As healthy tissue is spared at this temperature, whereas cancer cells display increased thermosensitivity, ${ }^{12,43,53}$ we set $41.5^{\circ} \mathrm{C}$ as the threshold of choice. Finally, cells free of ML served as a control.

\section{Cell Survival of MFH-Treated Mia PaCa-2 and PANC-I Cells}

Immediately after 90 minutes of MFH treatment, the viability was reduced significantly for both cell lines with solely extracellular ML's. After 24 hours, this group still was the one with the largest effect of MFH treatment on cell viability. In addition, for PANC-1, there was also a significantly reduced survival in the intra- and extracellular group (Figure 3B and D). A reason for this may lie in the slightly lower temperatures reached by other groups due to partial internalization of ML into the cell. Internalized ML are incapable of undergoing Brownian motion, which is known to contribute to nanoparticlebased heat generation, ${ }^{54}$ in this way resulting in lower heating power. ${ }^{55}$ As all groups started with the same concentration of ML with the assumption that a concentration of $225 \mu \mathrm{g}(\mathrm{Fe}) / \mathrm{mL}$ is achieved by endoscopic targeting at the tumor site, the extracellular ML concentration in the medium was reduced in the 'intra-and extracellular ML' by the amount of ML uptaken by the cells. The delayed effect of MFH on intracellularly placed ML in PANC-1 as seen in Figure 3D, is in line with data demonstrating delayed-onset kinetics for intracellular MFH-derived cytotoxicity on DX3 human melanoma cells. ${ }^{56}$

Although the effects of exclusively intracellular MLderived MFH solely amounted for minor to neglectable alterations in cell viability, intracellularly located ML may still be valued as a promising tool as certain therapeutics such as the chemotherapeutic drug gemcitabine may be significantly augmented in its efficiency by intracellular 
delivery. ${ }^{21,57}$ Based on this, a favorable synergistic antitumor characteristic of intracellular MFH combined with intracellular drug delivery can be expected as MFH has already demonstrated a promising perspective when combined with a therapeutic agent in the experimental treatment of triple-negative breast cancer. $^{58}$ Future investigations exploiting this synergistic effect need to be employed to improve treatment efficiency. In accordance with data showing delayed-onset kinetics for RAW-264.7 murine macrophage cells treated with intra- and extracellular $\mathrm{MFH}^{59}$ an explanation might be apoptosis-inducing pathways. These are triggered by intra- and extracellular $\mathrm{MFH}$, which then cause delayed cell death, in addition to the primary effect. Supporting this hypothesis, intra- and extracellular MFH also depicted lower cell viability over time, arguing in favor of the above proposed delayed-onset cytotoxicity. Further analysis of these apoptosis pathways in MFH is required. ${ }^{59-61}$ As this experiment was performed under the presumption that a concentration of $225 \mu \mathrm{g}(\mathrm{Fe}) / \mathrm{mL}$ is achieved by endoscopic targeting, we showed that the AMF may be applied directly after targeting or a modification of the surrounding layer of the ML may stop fast internalization of ML in tumor cells if not necessary.

\section{Clonogenic Potential of MFH-Treated Mia PaCa-2 and PANC-I Cells}

Tumor progression essentially relies on the self-renewal properties of its cells, as this ability holds the cause of cancer spreading, especially regarding metastasis development and disease relapse after successful treatment. ${ }^{62}$ Investigating the long-term effects of MFH treatment, we quantified this so-called clonogenic potential upon MFH treatment using clonogenic assays which represent the gold standard for testing the effectiveness of therapies. ${ }^{46}$ The results of our clonogenic assay tests (Figure 4) are in line with the cell viability tests as there is a late-onset effect and, in addition, extracellular placement of ML plays the most important role. For Mia PaCa-2, all groups resulted in a significant decrease of colonies, with hardly any formation of colonies for intra- and extracellular ML as well as extracellular ML (Figure 4A). MFH treatment of the PANC-1 cell line also resulted in a highly significant decrease in colony formation for all preparations (Figure 4B). Nonetheless, in all three treatment methods, the cells of this cell line were able to build colonies after MFH treatment. In summary, for both cell lines, the highest effect was found for solely extracellular ML (Figure 4).

By this, we not only contribute to previous reports on long-term cytotoxic effects of intracellular MFH and intraand extracellular $\mathrm{MFH}$ on Mia $\mathrm{PaCa}-2$ cells $^{12}$ but also complement these findings by insights into the superiority of extracellular MFH over intra- and extracellular MFH for different cell lines. Also, the results show that sensitivity towards MFH varies among different PDAC cell lines. Altering therapy responses upon thermal ablation, which is not MFH derived, is a known phenomenon in experimental hyperthermia treatment of PDAC. ${ }^{61,63,64}$ The superior thermotolerance of PANC-1 cells might arise from enhanced a priori tumorgenicity presented by this cell line, when compared to Mia PaCa-2 which was previously demonstrated by Gradiz et al. ${ }^{65}$ Still, the decrease in survival fraction was significant for both cell lines and all MFH treatment manners, with extracellular ML providing the highest effect for both cell lines. This, again, suggests that successful MFH may be performed by administration of ML immediately before the treatment and that pre-incubating with ML does not achieve higher effectiveness.

\section{MFH Treatment of Human PDAC Organoids}

Despite its numerous advantages and essential uses, 2D cell culture provides a rather artificial model of the real in vivo settings. Human patient-derived PDAC organoids are capable of partly overcoming this limitation as they possess the ability to mirror their primary tumor's key features such as geno- and phenotype ${ }^{38}$ as well as histoarchitecture and microenvironment in 3D structures with precise resemblance of actual in vivo conditions. ${ }^{42,47}$ The technique of organoids has been described in 2010 for the first time and has been improved ever since. ${ }^{42,66}$ It provides the opportunity to also model cell-cell interactions, ${ }^{37}$ which is why it has been used more and more for testing of therapy sensitivity ${ }^{37,39,40}$ and personalized treatment approaches. ${ }^{41}$ In this study, we employed MFH treatment of PDAC organoids to obtain information on the applicability of MFH treatment on threedimensional PDAC structures.

For the first time, we introduced magnetic nanoparticles to patient-derived organoids. Organoids, in general, grow in domes of a basement membrane extract, and there are no data on how to apply MFH on cells in this matrix. 
As the ability of nanoparticles to undergo Brownian motion strongly depends on the viscosity of their surrounding fluid, ${ }^{15}$ we compared the two standard set-ups for testing organoids regarding their heat development (Figure 5). We observed no significant difference and, therefore, used the set-up of growing the organoids in a dome and adding the ML via the media for the MFH experiments on human PDAC organoids.

Regarding the cytotoxicity of ML on PDAC organoids, our results (Figure 7) proved that in our preferred setting of a concentration of $225 \mu \mathrm{g}(\mathrm{Fe}) / \mathrm{mL}$, neglectable toxicity occurred as opposed to the positive control of DMSO. This was confirmed by IHC staining for $\mathrm{Ki} 67$ and $\mathrm{CC} 3$ which showed no significant alterations among ML-treated organoids and organoids free of ML exposure (Figure 8). Therefore, we performed the MFH experiments on organoids with this ML concentration at the tumor site. Addressing the effects of MFH on the cell viability of PDAC organoids, we used the approach with solely extracellularly placed ML as this provided the best results in the 2D cell culture already. As shown by Prussian blue staining, after 2 hours of incubation, ML showed no signs of internalization into the cells and interacted solely with adhesion to the cell surface (Figure 8). The absence of ML in the 'experiment setting' sample may be attributed to the multiple washing steps detaching ML from the cell surface. For both MFH approaches, immediate viability analysis and analysis after 24 hours, the AMF-treated samples showed significantly decreased viability (Figure 9). This is in line with our previous experiments on $2 \mathrm{D}$ cell lines. The immediate effect seems to even exceed the effect in either cell line in 2D cell culture (Figure 9A). After 24 hours, the effect was still noticeable, but not as distinct (Figure 9B). Whether this may be attributed to the more complex system of organoids being able to partially compensate the detrimental effects caused by MFH or a temporary reduction of their ATP production needs to be investigated further.

Based on previously stated beneficial characteristics of sequential thermal ablation of PDAC cells increasing treatment efficiency, ${ }^{64}$ we presume that short-term cytotoxicity of human PDAC tumors may also be enhanced by sequential treatment. This seems to be even more important in complex 3D structures with cell-cell interactions. Therefore, we will carry out further investigations on human PDAC organoids.

Our study holds some limitations. We used only two conventional 2D cell lines to evaluate the short- and long- term effects of MFH treatment on pancreatic cancer cells. Nonetheless, we chose these two lines as MiaPaCa-2 is a cell line very often used when investigating treatment response in PDAC, ${ }^{67-69}$ whereas PANC-1 is known to show more resistance towards treatment concepts. ${ }^{70,71}$ The treatment of PDAC organoids has only been performed on one patient-derived organoid culture. However, this is, to our knowledge, the first description of successful treatment of the advanced model of organoids with MFH. Still, PDAC organoids neither represent stromal tissue nor capillary networks essential for accurate insight on the dynamics of ML trapping. Therefore, in vivo experiments in animal models need to be employed to overcome this limitation, especially with regard to administration dose in the tumor tissue.

In conclusion, our results not only give first insight into the short- and long-term effects of MFH treatment on human PDAC cell lines and organoids but also show that MFH efficiency depends on the localization of the ML and, therefore, suggests that the time between endoscopic targeting of the ML at the tumor site and AMF application should be limited to minimum. In addition, we provide a proof of concept for MFH treatment of human PDAC organoids, providing the opportunity for further research of MFH effects using organoids. This work, therefore, shows how MFH treatment could be modified in order to qualify for optimal future clinical implementation.

\section{Acknowledgments}

The authors thank Sandra Jumpertz, Ilka Sauer, Nelli Neuberger, Merve Erdem and Jochen Nolting for their very valuable help with the cell culture experiments.

\section{Funding}

This work was in part funded by a research scholarship AAR received from the Medical Faculty of the RWTH Aachen University.

\section{Disclosure}

The authors reported no conflicts of interest for this work.

\section{References}

1. Bray F, Ferlay J, Soerjomataram I, Siegel RL, Torre LA, Jemal A. Global cancer statistics 2018: GLOBOCAN estimates of incidence and mortality worldwide for 36 cancers in 185 countries. CA Cancer J Clin. 2018;68:394-424. doi:10.3322/caac.21492

2. Siegel RL, Miller KD, Jemal A. Cancer statistics, 2017. CA Cancer J Clin. 2017;67:7-30. doi:10.3322/caac.21387 
3. Ferlay J, Soerjomataram I, Dikshit R, et al. Cancer incidence and mortality worldwide: sources, methods and major patterns in GLOBOCAN 2012. Int J Cancer. 2015;136:E359-E386. doi:10.10 02/ijc. 29210

4. Sant M, Aareleid T, Berrino F, et al. EUROCARE-3: survival of cancer patients diagnosed 1990-94-results and commentary. Ann Oncol. 2003;14(Suppl 5):v61-v118. doi:10.1093/annonc/mdg754

5. Brus C, Saif MW. Second line therapy for advanced pancreatic adenocarcinoma: where are we and where are we going?. JOP. 2010;11:321-323.

6. Stathis A, Moore MJ. Advanced pancreatic carcinoma: current treatment and future challenges. Nat Rev Clin Oncol. 2010;7:163-172. doi:10.1038/nrclinonc.2009.236

7. Scheufele F, Hartmann D, Friess H. Treatment of pancreatic cancer-neoadjuvant treatment in borderline resectable/locally advanced pancreatic cancer. Transl Gastroenterol Hepatol. 2019; 4:32. doi:10.21037/tgh.2019.04.09

8. Maebayashi T, Ishibashi N, Aizawa T, et al. Treatment outcomes of concurrent hyperthermia and chemoradiotherapy for pancreatic cancer: insights into the significance of hyperthermia treatment. Oncol Lett. 2017;13:4959-4964. doi:10.3892/ol.2017.6066

9. van der Horst A, Versteijne E, Besselink MGH, et al. The clinical benefit of hyperthermia in pancreatic cancer: a systematic review. Int J Hyperthermia. 2018;34:969-979. doi:10.1080/02656736.20 17.1401126

10. Wang L, Dong J, Ouyang W, Wang X, Tang J. Anticancer effect and feasibility study of hyperthermia treatment of pancreatic cancer using magnetic nanoparticles. Oncol Rep. 2012;27:719-726. doi:10.3892/ or.2011.1567

11. Yang F, Jin C, Subedi S, et al. Emerging inorganic nanomaterials for pancreatic cancer diagnosis and treatment. Cancer Treat Rev. 2012;38:566-579. doi:10.1016/j.ctrv.2012.02.003

12. Engelmann UM, Roeth AA, Eberbeck D, et al. Combining bulk temperature and nanoheating enables advanced magnetic fluid hyperthermia efficacy on pancreatic tumor cells. Sci Rep. 2018;8:13210. doi:10.1038/s41598-018-31553-9

13. Jordan A, Wust P, Scholz R, et al. Cellular uptake of magnetic fluid particles and their effects on human adenocarcinoma cells exposed to AC magnetic fields in vitro. Int J Hyperthermia. 1996;12:705-722. doi: $10.3109 / 02656739609027678$

14. Gilchrist RK, Shorey WD, Hanselman RC, Depeyster FA, Yang J, Medal R. Effects of electromagnetic heating on internal viscera: a preliminary to the treatment of human tumors. Ann Surg. 1965;161:890-896. doi:10.1097/00000658-196506000-00 008

15. Kötitz R, Fannin PC, Trahms L. Time domain study of Brownian and Néel relaxation in ferrofluids. J Magn Magn Mater. 1995;149:42-46. doi:10.1016/0304-8853(95)00333-9

16. Pakhomov AB, Bao Y, Krishnan KM. Effects of surfactant friction on Brownian magnetic relaxation in nanoparticle ferrofluids. $J$ Appl Phys. 2005;97:10Q305. doi:10.1063/1.1855195

17. Jordan A, Wust P, Fähling H, John W, Hinz A, Felix R. Inductive heating of ferrimagnetic particles and magnetic fluids: physical evaluation of their potential for hyperthermia. Int $J$ Hyperthermia. 1993;9:51-68. doi:10.3109/02656739309061478

18. Mitsumori M, Hiraoka M, Shibata $T$, et al. Development of intra-arterial hyperthermia using a dextran-magnetite complex. Int J Hyperthermia. 1994;10:785-793. doi:10.3109/0265673940901 2371

19. Soenen SJH, Himmelreich U, Nuytten N, de Cuyper M. Cytotoxic effects of iron oxide nanoparticles and implications for safety in cell labelling. Biomaterials. 2011;32:195-205. doi:10.1016/j.biomaterials. 2010.08.075

20. Cole AJ, Yang VC, David AE. Cancer theranostics: the rise of targeted magnetic nanoparticles. Trends Biotechnol. 2011;29: 323-332. doi:10.1016/j.tibtech.2011.03.001
21. Tang M, Svirskis D, Leung E, Kanamala M, Wang H, Wu Z. Can intracellular drug delivery using hyaluronic acid functionalised $\mathrm{pH}$-sensitive liposomes overcome gemcitabine resistance in pancreatic cancer? J Control Release. 2019;305:89-100. doi:10.1016/j. jconrel.2019.05.018

22. Sanhaji M, Göring J, Couleaud P, et al. The phenotype of target pancreatic cancer cells influences cell death by magnetic hyperthermia with nanoparticles carrying gemicitabine and the pseudo-peptide NucAnt. Nanomedicine. 2019;20:101983. doi:10.1016/j.nano.2018. 12.019

23. Brero F, Albino M, Antoccia A, et al. Hadron therapy, magnetic nanoparticles and hyperthermia: a promising combined tool for pancreatic cancer treatment. Nanomaterials. 2020;10:1919. doi:10.3390/ nano10101919

24. Jordan A, Scholz R, Maier-Hauff K, et al. The effect of thermotherapy using magnetic nanoparticles on rat malignant glioma. $J$ Neurooncol. 2006;78:7-14. doi:10.1007/s11060-005-9059-z

25. Kawai N, Futakuchi M, Yoshida T, et al. Effect of heat therapy using magnetic nanoparticles conjugated with cationic liposomes on prostate tumor in bone. Prostate. 2008;68:784-792. doi:10.1002/ pros. 20740

26. Krishnan S, Diagaradjane P, Cho SH. Nanoparticle-mediated thermal therapy: evolving strategies for prostate cancer therapy. Int J Hyperthermia. 2010;26:775-789. doi:10.3109/02656736.2010. 485593

27. Silva AC, Oliveira TR, Mamani JB, et al. Application of hyperthermia induced by superparamagnetic iron oxide nanoparticles in glioma treatment. Int J Nanomed. 2011;6:591-603. doi:10.2147/IJN.S14737

28. Alphandéry E, Faure S, Seksek O, Guyot F, Chebbi I. Chains of magnetosomes extracted from AMB-1 magnetotactic bacteria for application in alternative magnetic field cancer therapy. ACS Nano. 2011;5:6279-6296. doi:10.1021/nn201290k

29. Johannsen M, Gneveckow U, Thiesen B, et al. Thermotherapy of prostate cancer using magnetic nanoparticles: feasibility, imaging, and three-dimensional temperature distribution. Eur Urol. 2007; 52:1653-1661. doi:10.1016/j.eururo.2006.11.023

30. Kikumori T, Kobayashi T, Sawaki M, Imai T. Anti-cancer effect of hyperthermia on breast cancer by magnetite nanoparticle-loaded anti-HER2 immunoliposomes. Breast Cancer Res Treat. 2009;113:435-441. doi:10.1007/s10549-008-9948-x

31. Li WM, Chiang CS, Huang WC, et al. Amifostine-conjugated $\mathrm{pH}$-sensitive calcium phosphate-covered magnetic-amphiphilic gelatin nanoparticles for controlled intracellular dual drug release for dual-targeting in HER-2-overexpressing breast cancer. $J$ Control Release. 2015;220:107-118. doi:10.1016/j.jconre1.2015.10.020

32. Maier-Hauff K, Rothe R, Scholz R, et al. Intracranial thermotherapy using magnetic nanoparticles combined with external beam radiotherapy: results of a feasibility study on patients with glioblastoma multiforme. J Neurooncol. 2007;81:53-60. doi:10.1007/s11060-0069195-0

33. Hashemi-Moghaddam H, Kazemi-Bagsangani S, Jamili M, Zavareh S. Evaluation of magnetic nanoparticles coated by 5-fluorouracil imprinted polymer for controlled drug delivery in mouse breast cancer model. Int J Pharm. 2016;497:228-238. doi:10.1016/j.ijpharm.2015.11.040

34. Roeth AA, Slabu I, Baumann M, et al. Establishment of a biophysical model to optimize endoscopic targeting of magnetic nanoparticles for cancer treatment. Int J Nanomedicine. 2017;12:5933-5940. doi:10. 2147/IJN.S132162

35. Slabu I, Roeth AA, Engelmann UM, et al. Modeling of magnetoliposome uptake in human pancreatic tumor cells in vitro. Nanotechnology. 2019;30:184004. doi:10.1088/1361-6528/ab033e

36. Piehler S, Wucherpfennig L, Tansi FL, et al. Hyperthermia affects collagen fiber architecture and induces apoptosis in pancreatic and fibroblast tumor hetero-spheroids in vitro. Nanomedicine. 2020; 28:102183. doi:10.1016/j.nano.2020.102183 
37. Park SE, Georgescu A, Huh D. Organoids-on-a-chip. Science. 2019;364:960-965. doi:10.1126/science.aaw7894

38. Baker LA, Tiriac H, Clevers H, Tuveson DA. Modeling pancreatic cancer with organoids. Trends Cancer. 2016;2:176-190. doi:10.1016/ j.trecan.2016.03.004

39. Pasch CA, Favreau PF, Yueh AE, et al. Patient-derived cancer organoid cultures to predict sensitivity to chemotherapy and radiation. Clin Cancer Res. 2019;25:5376-5387. doi:10.1158/1078-0432.CCR18-3590

40. Romero-Calvo I, Weber CR, Ray M, et al. Human organoids share structural and genetic features with primary pancreatic adenocarcinoma tumors. Mol Cancer Res. 2019;17:70-83. doi:10.1158/15417786.MCR-18-0531

41. Es HA, Montazeri L, Aref AR, Vosough M, Baharvand H. Personalized cancer medicine: an organoid approach. Trends Biotechnol. 2018;36:358-371. doi:10.1016/j.tibtech.2017.12.005

42. Boj SF, Hwang CI, Baker LA, et al. Organoid models of human and mouse ductal pancreatic cancer. Cell. 2015;160:324-338. doi:10.1016/j.cell.2014.12.021

43. Brade AM, Szmitko P, Ngo D, Liu FF, Klamut HJ. Heat-directed suicide gene therapy for breast cancer. Cancer Gene Ther. 2003;10:294-301. doi:10.1038/sj.cgt.7700570

44. Vaes RDW, van Dijk DPJ, Welbers TTJ, et al. Generation and initial characterization of novel tumour organoid models to study human pancreatic cancer-induced cachexia. J Cachexia Sarcopenia Muscle. 2020;11:1509-1524. doi:10.1002/jcsm.12627

45. Hodenius M, Würth C, Jayapaul J, et al. Fluorescent magnetoliposomes as a platform technology for functional and molecular MR and optical imaging. Contrast Media Mol Imaging. 2012;7:59-67. doi:10.1002/cmmi.467

46. Franken NAP, Rodermond HM, Stap J, Haveman J, van Bree C. Clonogenic assay of cells in vitro. Nat Protoc. 2006;1:2315-2319. doi:10.1038/nprot.2006.339

47. Huang L, Holtzinger A, Jagan I, et al. Ductal pancreatic cancer modeling and drug screening using human pluripotent stem celland patient-derived tumor organoids. Nat Med. 2015;21:1364-1371. doi: $10.1038 / \mathrm{nm} .3973$

48. Soenen SJH, de Cuyper M. How to assess cytotoxicity of (iron oxide-based) nanoparticles: a technical note using cationic magnetoliposomes. Contrast Media Mol Imaging. 2011;6:153-164. doi:10.1002/cmmi.415

49. Mattson MP. Hormesis defined. Ageing Res Rev. 2008;7:1-7. doi:10.1016/j.arr.2007.08.007

50. Panyam J, Labhasetwar V. Dynamics of endocytosis and exocytosis of poly(D,L-lactide-co-glycolide) nanoparticles in vascular smooth muscle cells. Pharm Res. 2003;20:212-220. doi:10.1023/A:1022219003551

51. Dong J, Zink JI. Taking the temperature of the interiors of magnetically heated nanoparticles. ACS Nano. 2014;8:5199-5207. doi:10.1021/nn501250e

52. Dewhirst MW, Viglianti BL, Lora-Michiels M, Hanson M, Hoopes PJ. Basic principles of thermal dosimetry and thermal thresholds for tissue damage from hyperthermia. Int $J$ Hyperthermia. 2003;19:267-294. doi:10.1080/0265673031000119006

53. Ahmed K, Zaidi SF. Treating cancer with heat: hyperthermia as promising strategy to enhance apoptosis. J Pak Med Assoc. 2013;63:504-508.

54. Ng EY, Kumar SD. Physical mechanism and modeling of heat generation and transfer in magnetic fluid hyperthermia through Néelian and Brownian relaxation: a review. Biomed Eng Online. 2017;16:1-22. doi:10.1186/s12938-016-0292-9

55. Soukup D, Moise S, Céspedes E, Dobson J, Telling ND. In situ measurement of magnetization relaxation of internalized nanoparticles in live cells. ACS Nano. 2015;9:231-240. doi:10.1021/nn503888j
56. Blanco-Andujar C, Ortega D, Southern P, Nesbitt SA, Thanh NTK, Pankhurst QA. Real-time tracking of delayed-onset cellular apoptosis induced by intracellular magnetic hyperthermia. Nanomedicine. 2016;11(2):121-136. doi:10.2217/nnm.15.185

57. Lee GY, Qian WP, Wang L, et al. Theranostic nanoparticles with controlled release of gemcitabine for targeted therapy and MRI of pancreatic cancer. ACS Nano. 2013;7:2078-2089. doi:10.1021/nn3043463

58. Zhang Y, Hu H, Tang W, et al. A multifunctional magnetic nanosystem based on "two strikes" effect for synergistic anticancer therapy in triple-negative breast cancer. J Control Release. 2020;322:401-415. doi:10.1016/j.jconrel.2020.03.036

59. Beola L, Asín L, Fratila RM, et al. Dual role of magnetic nanoparticles as intracellular hotspots and extracellular matrix disruptors triggered by magnetic hyperthermia in 3D cell culture models. ACS Appl Mater Interfaces. 2018;10:44301-44313. doi:10.1021/acsami.8b18270

60. Kossatz S, Ludwig R, Dähring H, et al. High therapeutic efficiency of magnetic hyperthermia in xenograft models achieved with moderate temperature dosages in the tumor area. Pharm Res. 2014;31:3274-3288. doi:10.1007/s11095-014-1417-0

61. Ludwig R, Teran FJ, Teichgraeber U, Hilger I. Nanoparticle-based hyperthermia distinctly impacts production of ROS, expression of Ki-67, TOP2A, and TPX2, and induction of apoptosis in pancreatic cancer. Int J Nanomedicine. 2017;12:1009-1018. doi:10.2147/IJN.S108577

62. Marengo A, Forciniti S, Dando I, et al. Pancreatic cancer stem cell proliferation is strongly inhibited by diethyldithiocarbamate-copper complex loaded into hyaluronic acid decorated liposomes. Biochim Biophys Acta Gen Subj. 2019;1863:61-72. doi:10.1016/j. bbagen.2018.09.018

63. Lage H, Jordan A, Scholz R, Dietel M. Thermosensitivity of multidrug-resistant human gastric and pancreatic carcinoma cells. Int $J$ Hyperthermia. 2000;16:291-303. doi:10.1080/0265673 0050074069

64. Baumann KW, Baust JM, Snyder KK, Baust JG, van Buskirk RG. Characterization of pancreatic cancer cell thermal response to heat ablation or cryoablation. Technol Cancer Res Treat. 2017;16: 393-405. doi:10.1177/1533034616655658

65. Gradiz R, Silva HC, Carvalho L, Botelho MF, Mota-Pinto A. MIA PaCa-2 and PANC-1 - pancreas ductal adenocarcinoma cell lines with neuroendocrine differentiation and somatostatin receptors. Sci Rep. 2016;6:21648. doi:10.1038/srep21648

66. Clevers H. Modeling development and disease with organoids. Cell. 2016;165:1586-1597. doi:10.1016/j.cell.2016.05.082

67. Duong H-Q, Yi YW, Kang HJ, et al. Combination of dasatinib and gemcitabine reduces the ALDH1A1 expression and the proliferation of gemcitabine-resistant pancreatic cancer MIA PaCa-2 cells. Int J Oncol. 2014;44:2132-2138. doi:10.3892/ijo.2014.2357

68. Luo D, Carter KA, Geng J, He X, Lovell JF. Short drug-light intervals improve liposomal chemophototherapy in mice bearing MIA PaCa-2 xenografts. Mol Pharm. 2018;15:3682-3689. doi:10.1021/ acs.molpharmaceut.8b00052

69. Milanović D, Firat E, Grosu AL, Niedermann G. Increased radiosensitivity and radiothermosensitivity of human pancreatic MIA PaCa-2 and U251 glioblastoma cell lines treated with the novel Hsp90 inhibitor NVP-HSP990. Radiat Oncol. 2013;8:42. doi:10.1186/1748-717X-8-42

70. Santana-Codina N, Roeth AA, Zhang Y, et al. Oncogenic KRAS supports pancreatic cancer through regulation of nucleotide synthesis. Nat Commun. 2018;9:4945. doi:10.1038/s41467-018-07472-8

71. Singh A, Greninger P, Rhodes D, et al. A gene expression signature associated with "K-Ras addiction" reveals regulators of EMT and tumor cell survival. Cancer Cell. 2009;15:489-500. doi:10.1016/j. ccr.2009.03.022 


\section{Publish your work in this journal}

The International Journal of Nanomedicine is an international, peerreviewed journal focusing on the application of nanotechnology in diagnostics, therapeutics, and drug delivery systems throughout the biomedical field. This journal is indexed on PubMed Central, MedLine, CAS, SciSearch ${ }^{\mathbb{B}}$, Current Contents ${ }^{\mathbb{B}} /$ Clinical Medicine, $^{2}$
Journal Citation Reports/Science Edition, EMBase, Scopus and the Elsevier Bibliographic databases. The manuscript management system is completely online and includes a very quick and fair peer-review system, which is all easy to use. Visit http://www.dovepress.com/ testimonials.php to read real quotes from published authors. 